\title{
İstiridye mantarının (Pleurotus ostreatus) tohumluk misel üretimi üzerine bir ön çalışma
}

\section{A preliminary study on spawn production of oyster mushroom (Pleurotus ostreatus)}

\author{
Ahmet ÇAT, Turhan ÇOMAK, Mürsel ÇATAL \\ Akdeniz Üniversitesi, Ziraat Fakültesi, Bitki Koruma Bölümü, Antalya, Türkiye \\ Sorumlu yazar (Corresponding author): M. Çatal, e-posta (e-mail): mcatal@akdeniz.edu.tr
}

\section{MAKALE BILGISİ}

Alınış tarihi 13 Ekim 2017

Düzeltilme tarihi 15 Şubat 2018

Kabul tarihi 15 Şubat 2018

\section{Anahtar Kelimeler:}

İstiridye mantarı

Pleurotus ostreatus

Tohumluk

Yerli misel

\section{$\ddot{O Z Z}$}

İstiridye mantarı (Pleurotus ostreatus), Türkiye'de kültür mantarından (Agaricus bisporus) sonra en yaygın yetiștirilen mantar türüdür. Ülkemizde istiridye mantarı yetiștiriciliği 1980'li yıllarda başlamıştır. Ancak, Bu yıllarda kültür mantarı yetiştiriciliği de yaygınlaşmaya başlamış, aslında yetiştiriciliği kültür mantarına göre daha kolay olmasına rağmen İstiridye mantarı yetiştiriciliği yeteri kadar ilgi görmemiş ve yaygınlaşmamıştır. Kompost hazırlama gibi zahmetli bir işlemi gerektirmeyen istiridye mantarı meşe, kayın, gürgen gibi ağaç kütükleri ile lignin ve selülozca zengin her türlü tarımsal bitki artıkları kullanılarak kolaylıkla yetiştirilebilmektedir. İstiridye mantarı yetiştiriciliği sonunda ortaya çıkan bitkisel atıklar hayvan beslenmesi ve tarımsal üretimde farklı amaçlar için kullanılabilmektedir. Bu özelliklerin yanında, gıda olarak tüketilmesi durumunda besleyici özelliğinin fazla olması ve tıbbi amaçla kullanılabilmesinden dolayı, önemli bir gıda ve ham madde kaynağı olarak değerlendirmektedir. Ülkemizde son yıllarda istiridye mantarı yetiștiriciliğine olan ilgi dikkate değer şekilde artış göstermektedir. Bununla birlikte kültür mantarında olduğu gibi istiridye mantarı üretiminin en önemli girdisi olan tohumluk misel (spawn) yurtdışı kaynaklardan sağlanmakta ve her iki mantarın tohumluk misel üretimi için günümüze kadar tespit edilmiş ve ticarileştirilmiş yerli izolat veya kültürleri bilinmemektedir. Yurtdışı kökenli izolat veya kültürlerden elde edilen tohumların ithali ülkemiz mantar yetiștiricilerine ciddi bir ekonomik yük getirmektedir. Bu çalışmada yerli $P$. ostreatus izolatı kullanılarak tohumluk misel üretimi gerçekleștirilmiş ve üretilen tohumlar saman substratına sardırılarak istiridye mantarı üretimi ve verimi değerlendirilmiştir. Bu araştırma ile yerli tohumluk üretiminde bir adım atılarak bu konuda dışa bağımlılı̆̆ın azaltılması yönünde öncü bir çalışma yapılımışıır.

\section{ARTICLE INFO}

Received 13 October 2017

Received in revised form 15 February 2018

Accepted 15 February 2018

\section{Keywords:}

Oyster mushroom

Pleurotus ostreatus

Seedling

Native spawn

\begin{abstract}
Oyster mushroom (Pleurotus ostreatus) is the most commonly grown mushroom species after white button mushroom (Agaricus bisporus) in Turkey. The cultivation of Pleurotus spp. dates back to 1980's in the country. The cultivation of white button mushrom has also become quite common in the same years. Although Oyster mushroom is easier to grow than white button mushroom, the cultivation of this mushroom has not attracted the attention of the growers hence not grown widely. This mushroom species does not require laborsome work such as compost preparation and can be easily grown on oak, ash and poplar stumps and agricultural waste products rich in cellulose and lignin. Furthermore, wastes of Oyster mushroom cultivation can be used in animal feeding and agricultural production. In addition to these properties, the mushroom is an important food and raw material source in human nutrition and health as it has significant nutritional and medicinal values. The interest in Oyster mushroom cultivation has increased noticeably in recent years in the country. However, as in white button mushroom, the mushroom spawn which is the most important input of oyster mushroom production is obtained from foreign sources. Up to date, there has not been any native isolates or cultures of both mushroom species that were identified and commercialized for spawn production in the country. Importation of mushroom spawn produced from isolates originated or developed in other countries put a heavy economic burden on the growers and the country. In this study, mushroom spawn was produced from a native isolate of $P$. ostreatus, and the growth potential and yield of the isolate were evaluated by inoculating the spawn onto wheat straw compost. This is a pioneer research to produce mushroom spawn domestically and to reduce the dependence on foreign spawn supply.
\end{abstract}




\section{Giriş}

İstiridye mantarı (Pleurotus ostreatus) kültür mantarından (Agaricus bisporus) sonra Dünya'da en çok üretilen kültür mantarı türüdür. Ülkemizde halk arasında kavak, kayın, dil, kulak, melek mantarı vb. yöresel isimleriyle bilinmektedir. Bu mantar dünyanın neredeyse bütün 1lıman iklim bölgelerinde; kavak, kayın, meşe, karaağaç, akçaağaç, ıhlamur, söğüt, ceviz ve kestane gibi birçok ağaç türünün gövdelerinde doğal olarak yetişmektedir. İstiridye mantarı yüksek protein ve farklı vitaminleri içermesi, yağ oranının az olması ile çeşitli mineral maddeler içermesi sebebiyle değerli bir besin maddesi olarak değerlendirilmektedir. Ek olarak mantarın içeriğinde bulunan bazı proteinlerden dolayı da sindirimi kolaydır. İstiridye mantarı, insan sağlığı açısından yüksek besin değeri, sahip olduğu hoş koku ve lezzet bakımından değerli bir protein kaynağıdır (Poppe 2000). İstiridye mantarı B1, B2, B3, B5, C ve $\mathrm{D}$ vitamini içeriğine sahip olan önemli bir mantar türüdür (Jonathan 2012). Ekonomik ve besinsel değerinin yanı sıra tıbbi önemede sahip bir mantar türüdür. $P$. ostreatus ve diğer bazı yakın akraba türler ABD Federal İlaç Otoritesi (FDA) tarafindan onaylanan etken maddesi "Lovastatin" (3-hidroksi3-metilglutaril-coenzim-A reduktaz) olan ilaçları doğal olarak üretmektedir. Etken madde, mantarın daha çok şapka kısmında ve olgun lameller ile sporlarının içerisinde bulunmaktadır. Yapılan çalışmalar sonucunda etken maddenin kandaki aşırı kolesterol seviyesini düzenlenmede, azaltmada ve tümor oluşumunu engellemede etkili olduğu belirlenmiştir (Bobek ve ark. 1995; Fukushima ve ark. 2001).

P. ostreatus son yıllarda hidrofobik özelliğe sahip hydrofobinler üretimi (Ma ve ark. 2008), yüksek lignin-selüloza parçalama aktivitesi (Marques ve ark. 2010; Lettera ve ark. 2011; Piscitelli ve ark. 2011; Ruiz-Duenas ve ark. 2011), tarımsal endüstri atıklarının biyolojik dönüşümü (Shabtay ve ark. 2009; Salvachua ve ark. 2011) ve sürdürülebilir bir çevre sağlığı/koruma için toksik ağır metallerin biyolojik absorbsiyonunda kullanımı (Pan ve ark. 2005) gibi çeşitli endüstriyel, biyoteknolojik ve çevresel uygulamalardaki kullanımı ile de ön plana çıkmaktadır (Irie ve ark. 2001; Cohen ve ark. 2002). P. ostreatus'un yetiştirilmesinde kullanılan samanın, hayvanın kanındaki metabolit ve beslenme davranışı üzerine herhangi bir zararlı etkisi olmaksızın büyükbaş hayvan beslenmesinde kullanılabileceği bildirilmiştir (Silvana ve ark. 2006). Ayrıca samanın P. ostreatus tarafından parçalanması ile hayvan beslenmesi açısından besin değerinin ve sindirilebilirliğinin arttığ 1 belirtilmiştir (Adamovic ve ark. 1998).

Yetiştirme ortamı için fermente olmamış materyal kullanılması, yetiştirildiği ortamın iklim koşullarından sınırlı düzeyde etkilenmesi, hastalık ve zararlılara karşı kabul edilebilir düzeyde dayanıklı olması $P$. ostreatus'un üretimini diğer mantar türleri ile karşılaştırıldığında daha cazip hale getirmektedir. $A$. bisporus'dan farklı olarak, yetiştiricilik sürecince hastalık etmenlerinden sinırlı düzeyde etkilenmesi ve fermente olmamış kompostun kullanılabilmesi diğer avantajları arasındadır (Sanchez 2010).

Çok farklı bitkisel materyal üzerinde yetiştirilebilen ve birim alandan memnun edici düzeyde verimin elde edildiği $P$. ostreatus'un çok sayıda 1rk1 olup bu ırklarının neredeyse tümünün yetiştirmesi kolaydır. Dünya da haklı bir üne sahip mantarın ticarete konu olan önemli örnekleri doğadan toplanmış, kültüre alınmış ve yüksek düzeyde verime sahip ırkları elde edilerek ticarete konu edilmiştir (Stamets 2000).
Ülkemizde yaygın şekilde yetiştiriciliği yapılan kültür mantarı çok sayıda hastalık etmenine hassas olduğu bilinmekte olup, istiridye mantarı yetiştiriciliğinde sorun olan önemli bir hastalık rapor edilmemiştir (Sanchez 2010).

$\mathrm{Bu}$ çalışmayla, ülkemizde yetiştiriciliği ve üretimi son yıllarda hızla artan fakat tohumları tamamen yurtdışından ithal edilen $P$. ostreatus tohumluk misellerinin yerine fungusun yerli bir izolatının kullanılması ile hazırlanması ve mantar üretiminin yapılması amaçlanmıştır. Dünyada ve ülkemizde mevcut ticari tohumluk üretiminde kullanılan izolatların patentleri tohumluk misel satan sinırlı sayıda ticari firmanın tekelinde bulunmaktadır. $\mathrm{Bu}$ nedenle ülkemize özel yerli $P$. ostreatus izolatlarının tespit edilip mantar tohumu üretiminde kullanılma potansiyellerinin belirlenmesi gerekmektedir. Yürütülen çalışma ile yerli $P$. ostreatus izolatı kullanılarak yerli tohumluk misel üretimi yapılması, sonrasında ülkemizin tohumluk misel ihtiyacının bağımlılığının sınırlandırılması hedeflenmiştir.

\section{Materyal ve Yöntem}

\subsection{Pleurotus ostreatus'un teşhis ve tanısı}

Çalışma kapsamında Akdeniz Üniversitesi Merkez Yerleşkesi (Konyaaltı/Antalya) içerisinde bulunan gladiçya ağacının (Gleditsia triacanthos L.) (Fabaceae) gövdesinde ilk kez istiridye mantarı (P. ostreatus) tespit edilmiştir. P. ostreatus mantarının teşhisi şapka yapısı ve rengi, sapın şapkaya bağlanma şekli ve yapısı gibi makroskobik özellikler yanında sporizinin çıkarılması (spore printing) ile elde edilen sporların rengi, şekli, büyüklükleri gibi mikroskobik özellikler incelenerek teşhis anahtarı kullanılarak yapılmıştır (Arora 1986; Stamets 2000). Şapka yapısı başlangıçta konveks şeklinde olup sonra daha da genişleyerek düzleşmektedir. Şapka gri renkli ve çapı 5-15 cm arasındadır. Şapka kenarları başlangıçta içe doğru kıvrık, gilleri şapkadan sapa doğru akan (decurrent) şekilde bağlanmıştır. Spor izi ve spor rengi beyazdır. Sporların şekli yumurta ve eliptik şekilde olup boyutları 3-4x7-9 mikrometre $(\mu \mathrm{m})$ arasındadır.

\subsection{Pleurotus ostreatus saf kültürlerin elde edilmesi}

Saf kültürleri elde etmek için malt ekstrakt pepton agar (MEPA; $30 \mathrm{~g}$ malt ekstrakt, $3 \mathrm{~g}$ pepton, $15 \mathrm{~g}$ agar, 11 distile $\mathrm{su}$ ) besi ortamı kullanılmıştır (Girmay ve ark. 2016). Steril kabin içerisinde $P$. ostreatus örneklerinin şapka ve sap kısımlarından steril bistüri ile alınan parçalar steril Petri kaplarında bulunan MEPA besin ortamına aktarıldıktan sonra Petri kabı her türlü kontaminasyonu engelleyecek şekilde izole edilmiş ve karanlık ortamda $25^{\circ} \mathrm{C}$ 'de inkübasyon ortamına alınarak fungus kültürünün gelişmesi sağlanmıştır (Şekil 1). Petri kabı içerisindeki misel gelişimi Petri ortamını kapladıktan sonra elde edilen saf kültürler kullanılıncaya kadar kısa süreli depolama için buzdolabında $+4{ }^{\circ} \mathrm{C}$ 'de, uzun süreli depolama için eğik agar tüplerinde saklanmıştır (Stamets 2000). Bu çalışmalara ek olarak kültür $15 \mathrm{~cm}$ x $15 \mathrm{~cm}$ boyutunda steril edilmiş kapaklı kare cam üzerinde spor izleri (spor printing) üretilerek hem bu sporlardan saf fungus kültürü elde edilmiş hem de fungusun sporları elde edilerek farklı kullanım amaçları için uzun süre muhafazası sağlanmıştır.

\subsection{Pleurotus ostreatus tohumluk misel üretimi}

Mantar tohumluk miseli (spawn) elde etmede sardırma materyali olarak iyi temizlenmiş, içinde yabancı ot tohumları bulunmayan ve tüm hastalıklardan ari steril edilmiş çavdar 


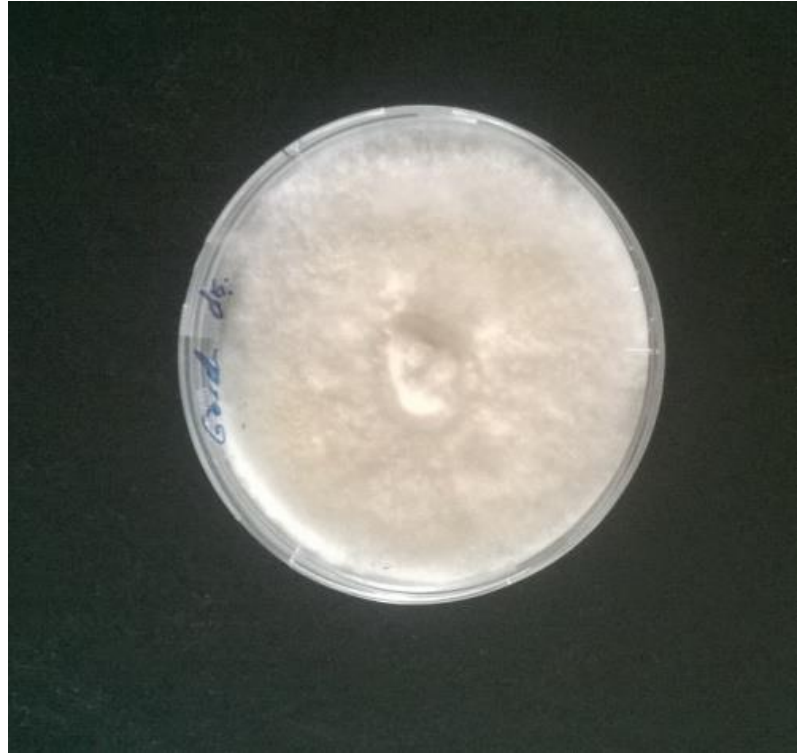

Şekil 1. Mantarın sap kısmından elde edilen saf Pleurotus ostreatus kültürü.

Figure 1. Pleurotus ostreatus culture isolated from the mushroom stalk.

tanelerikullanılmıştır (Stamets 2000). Bu amaçla steril bir litrelik cam kavanozların her birine $200 \mathrm{~g}$ çavdar, $1 \mathrm{~g}$ alçı tozu ve $200 \mathrm{ml}$ distile su konularak bir gece bekletilmiştir. Alçı tozu çavdar tanelerinin birbirine yapışmaması için ilave edilmiştir. Hazırlanan ortam 24 saat sonra kavanoz kapakları ortasından delinmiş ve bu delinen kısımlara pamuk konularak $121{ }^{\circ} \mathrm{C}$ 'de bir saat süreyle otoklav ortamında steril edilmiştir. Steril edilen besi ortamı kavanozların içine 2 haftalık MEPA ortamı üzerinde geliştirilen $P$. ostreatus'un misel parçaları (2-3) ilave edilerek aşılama yapılmıştır (Stamets 2000). Kavanozlar dört günlük aralıklarla misel büyümesinin yeknesak bir şekilde olması ve çavdar danelerini tamamen sarması için çalkalanmıştır (Holkar ve Chandra 2016).

\subsection{Pleurotus ostreatus'un substrat materyaline sardirlmasl ve verim değerlendirilmesi}

$P$. ostreatus izolatının çalışmada elde edilen miselleri kullanılarak hazırlanan buğday samanı kompost materyaline sardırılmıştır. Substratı hazırlamak için kuru buğday samanı su içerisinde 18 saat bekletilmiş olup suyu süzüldükten sonra $121^{\circ} \mathrm{C}^{\prime} \mathrm{de}$ otoklav edilmiştir. Uygulama sonrasında elde edilen saman, steril koşullarda oda sıcaklığında bekletilip soğutulduktan sonra $40 \mathrm{~cm}$ x $40 \mathrm{~cm}$ boyutundaki polietilen torbalara yarım kilo olacak şekil de koyulmuştur. Hazırlanan bu substrat ortamına çavdar tanelerine sardırılmış tohumluk miseller eklenerek ortam karıştırılarak aşılama yapılmıştır (Holkar ve Chandra 2016). Karıştırma oranı tohumluk miseller substrat materyalinin \% 2-3'ü olacak şekilde yapılmıştır. Karıştırma işlemi sonrasında polietilen torbalara rastgele delikler açılarak ortam havasının girişi sağlanmıştır. Steril uygulamalara uygun olarak gerçekleştirilen aşılamanın ardından torbalar Akdeniz Üniversitesi Ziraat Fakültesi bünyesinde yer alan iklim odasına yerleştirilmiş ve $22-24{ }^{\circ} \mathrm{C}$ de inkubasyona ortamına alınmıştır. Mantar miselinin saman kompostunu tamamen sarmasına sonrasında ortam sicaklığ $14-16^{\circ} \mathrm{C}$ ye ayarlanmıştır. Verim aşamasında mantarın yalnızca biyolojik verimi (g) aşılama yapılan her bir polietilen torbadan rastgele seçilen mantar demetlerinin sap ve taban kısmının tartılmasıyla belirlenmiştir (Girmay ve ark. 2016).

\section{Bulgular ve Tartış̧ma}

$P$. ostreatus'un saf kültürlerinin elde edilmesi için yaygın olarak doku kültürü ve sporlardan izolasyon ile çoğaltma yöntemi kullanılmıştır (Stamets 2000). P. ostreatus' un kültürde gelişimi için çok sayıda farklı besi ortamı mevcuttur. Bununla birlikte yapılan çalışmaların çoğunda MEA (Stamets 2000; Nasim ve ark. 2001; Girmay ve ark. 2016) ve PDA (Kumla ve ark. 2013; Liu ve ark. 2013; Ojwang ve ark. 2015; Holkar ve Chandra 2016) besi ortamları tercih edildiğinden bu çalışmada da MEA besi ortamı tercih edilmiştir. Teşhis edilen istiridye mantarının şapka ve sap kısımlarından alınan parçalar kültüre alınarak mantarın izolatı elde edilmiştir (Şekil 1). $P$. ostreatus'un misel tohum üretim çalışmaları ile ilgili yapılan araştırmalarda, genellikle izlenen aşamalar benzer olmakla birlikte misel üretimi için kullanılan sardırma materyalleri ve misel miktarlarında farklılıklar olduğu bildirilmektedir (Iqbal ve ark. 2005; Girmay ve ark. 2016; Holkar ve Chandra 2016). Literatürde $P$. ostreatus'un tohumluk misel üretiminde tahıl taneleri ve odun talaşı yaygın olarak kullanıldığ bildirilmektedir. $\mathrm{Bu}$ çalışmada misel sarımı için çavdar tanelerinin kullanılması tercih edilmiştir (Şekil 2). Elde edilen izolatın misellerinin çavdar tanelerini $24{ }^{\circ} \mathrm{C}^{\prime} \mathrm{de} 2$ hafta gibi kısa bir sürede tamamen sardığı belirlenmiştir. Çavdar, buğday, sorgum, darı ve mısır gibi ürünlerin tanelerine sardırılarak hazirlanan tohumluk miseller $P$. ostreatus'un kapalı yerlerde üretiminde odun talaşına sardırılarak hazırlanan tohumlar ise ağaç kütük ve gövdelerine aşılama ile üretimde tercih edildiği bildirilmektedir (Stamets 2000). Çalışmada kullanılan izolatın istiridye mantarının gelişim süresi dikkate alındığında hızlı ve etkin bir sarım gücüne sahip olduğu görülebilmektedir.

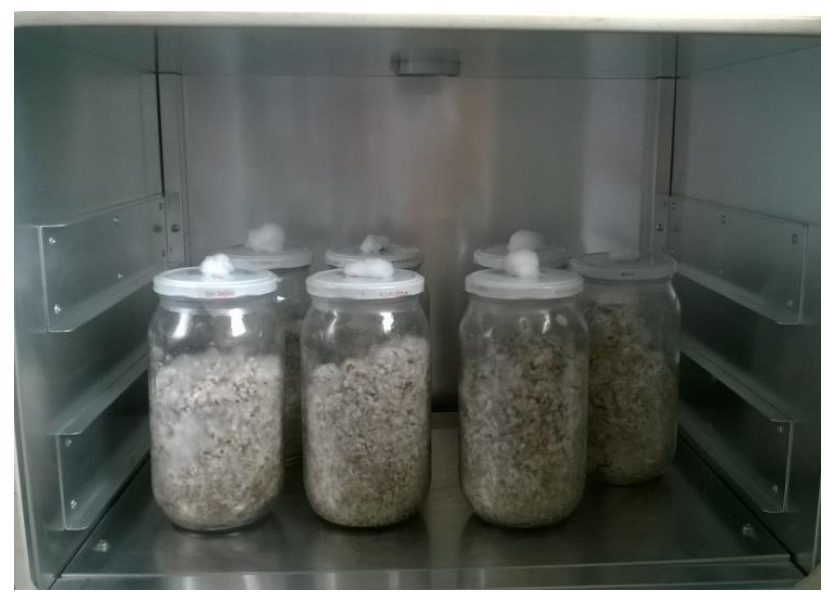

Şekil 2. Pleurotus ostreatus misellerinin tohumluk misel üretimi için çavdar tanelerine sardırılması.

Figure 2. The Pleuorotus ostreatus mycelia colonizing the rye seed for spawn production.

P.ostreatus çok farklı tarımsal ve orman ürün artıklarında yetiştirilebilmektedir. $\mathrm{Bu}$ atık ürünlerle hazırlanan istiridye üretim ortamlarına gelişimi ve gelişimi teşvik eden çeşitli maddeler ilave edilerek $P$. ostreatus'un verim ve kalite özelliklerinin istenilen yönde geliştirilmesi için en uygun olabilecek yetiştirme ortamı/ortamları yapılan birçok araştırmada belirlenmiştir (Oseni ve ark. 2012; Pala ve ark. 2013; Pokhrel ve ark. 2013; Holkar ve Chandra 2016). Tahıl samanları (buğday, çavdar, yulaf, pirinç ve arpa), mısır sapları, şekerkamışı küspesi, kahve, çekirdek, bitki artıkları, muz, meyve, bitkisel artıkları, pamuk tohumu, odun talaşları, kağıt 
ürünleri, soya fasulyesi ve diğer bir çok bitkisel ürün artıklar istiridye mantarının yetiştirilmesinde kullanılabilmektedir. Birçok çalışmada $P$. ostreatus'un bu yetiştirme ortamlarındaki büyüme ve verim parametreleri belirlenmiştir (Stamets 2000; Rajak ve Basu 2011; Girmay ve ark. 2016; Holkar ve Chandra 2016). Çalışmada istiridye mantarının bu izolatı için kullanılan gelişim parametreleri Çizelge 1'de belirtilmiştir. Mantar miselinin büyüme ve koloni karakterleri dikkate alındığında, çalışmada kullanılan izolatın istiridye mantar üretimi için uygun bir aday olabileceği tespit edilmiştir. Gelişim parametrelerine uygun olarak buğday samanı substratına misellerin sardırılması Şekil 3'de, primordium oluşumu Şekil 4'de ve mantar gelişimi ise Şekil 5'de verilmiştir. Her geliştirme ortamı içerisine $500 \mathrm{~g}$ buğday samanı bulunan polietilen ortamlardan ortalama 100 ila $120 \mathrm{~g}$ ürün elde edilmiştir.

Çizelge 1. Çalışmada kullanılan izolatın gelişim parametreleri. Table 1. Growth parameters of the isolate used in the study.

Büyüme parametreleri Nisbi nem (\%) Süre (gün) Sıcaklık $\left({ }^{\circ} \mathrm{C}\right)$

\begin{tabular}{lccc}
\hline Misel öngelişimi & $\% 95$ & 14 & 24 \\
Primordium oluşumu & $\% 95$ & 7 & $14-16$ \\
Mantar gelişimi & $\% 90$ & $7-10$ & 18 \\
\hline
\end{tabular}

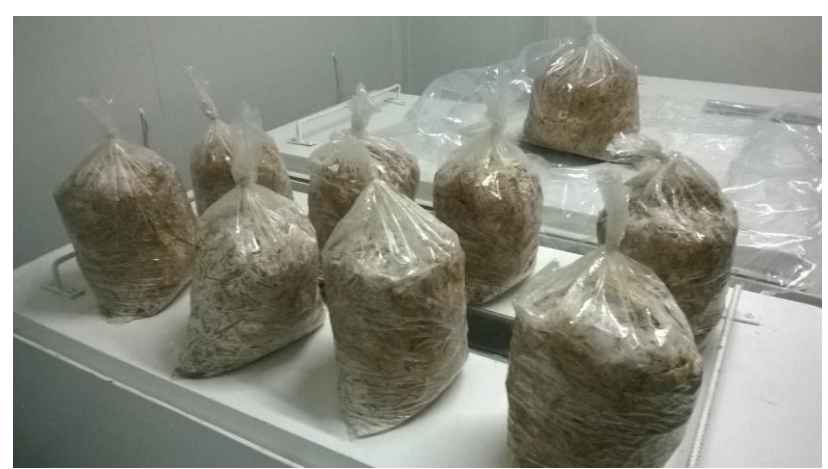

Şekil 3. Mantar tohumluk misellenin hazırlanan buğday samanı substratına aşılanması.

Figure 3. Inoculation of the mushroom spawn into wheat straw compost.

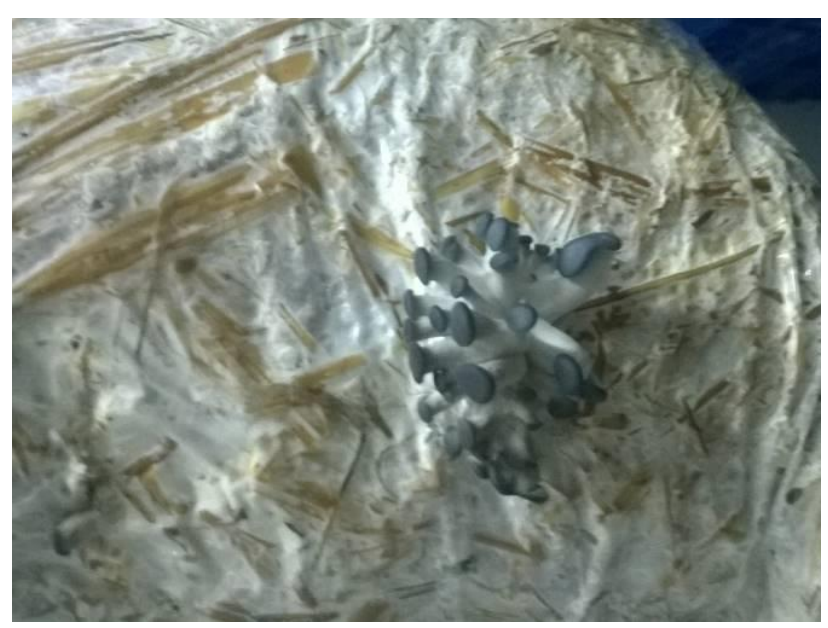

Şekil 4. İstridye mantar primordiumlarının oluşumu.

Figure 4. Primordia formation of Oyster mushroom.

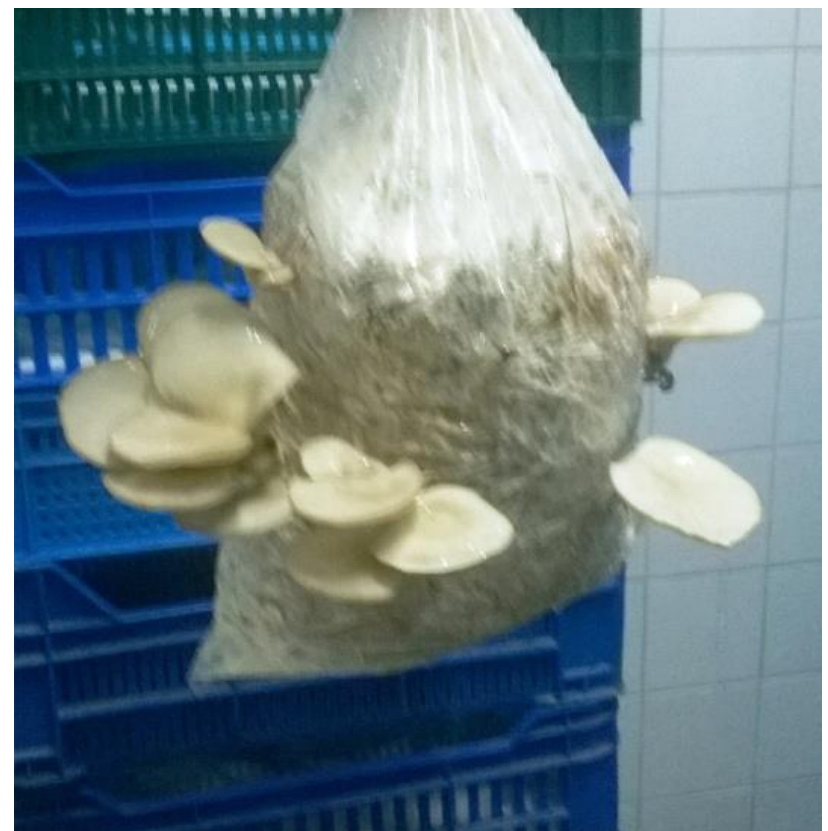

Şekil 5. Bugday saman subsratı üzerinde istiridye mantarı gelişimi.

Figure 5. Oyster mushroom growth on wheat straw compost.

\section{Sonuç}

Dünyada ve Türkiye' de gittikçe kullanımı ve pazar payı artan, gida olarak kullanıldığ 1 durumlarda besin ve alternatif olarak kullanıldığ tıbbi özelliklerinin istenilen seviyede olan $P$. ostreatus'un yerli tohumluk misel üretimi ile ilgili ülkemizde herhangi bir çalışmaya rastlanmamıştır. Ülkemizde ticari yetiştiriciliğin yapılması konusundaki çalışmalar ise sınırlıdır. Dünya mantar sektöründe önemli konumda olan istiridye mantarının yetiştiriciliğinin ülkemizde de yaygınlaştırılması büyük önem arz etmektedir. Ülkemizde yetiştiriciliği son yıllarda $\operatorname{artan} P$. ostreatus 'un tohumluk miseller yurt dişından ithal edilmektedir. Diğer taraftan Ülkemizde ki mevcut ticari tohumluk üretiminde kullanılan izolatların patentleri tohumluk misel satan ticari kuruluşların elinde bulunmaktadır. Yapılan araştırma ülkemizde toplanmış bir $P$. ostreatus izolatı kullanılarak yerli mantar tohumu ve mantar üretiminin yapıldığg az sayıdaki çalışmalardan birisidir. Çalışmada elde edilen izolatın besi ortamında sektörleşme olmadan gelişimi, tohumluk üretmek için kullanılan çavdar tanelerini hılı bir şekilde sarması ve substrata sarım ile büyüme ve verim değeri göz önüne alındığında istiridye mantarı üretiminde kullanılabileceği belirlenmiştir.

\section{Kaynaklar}

Adamovic M, Grubic G, Milenkovic I, Jovanovic R, Protic R, Sretenovic L, Stoicevic L (1998) The biodegradation of wheat straw by Pleurotus ostreatus mushrooms and its use in cattle feeding. Animal Feed Science Technol 71: 357-362.

Arora D (1986) Mushrooms Demystified. Ten Speed Press, $2^{\text {nd }}$ edn. Berkeley, California.

Bobek P, Ozdin O, Mikus M (1995) Dietary oyster mushroom (Pleurotus ostreatus accelerates plasma cholesterol turnover in hypercholesterolaemic rats. Physiol. Res 44: 287-291.

Cohen R, Persky L, Hadar Y (2002) Biotechnological applications and potential of wood-degrading mushrooms of the genus Pleurotus. Appl Microbiol Biot 58: 582-594. 
Fukushima M, Ohashi T, Fujiwara Y, Sonoyama K, Nakano M (2001) Cholesterol-lowering effects of maitake (Grifola frondosa) fiber, shiitake (Lentinus edodes) fiber, and enokitake (Flammulina velutipes) fiber in rats. Exp Biol Med (Maywood) 226: 758-765.

Girmay Z, Gorems W, Birhanu G, Zewdie S (2016) Growth and yield performance of Pleurotus ostreatus (Jacq. Fr.) Kumm (Oyster Mushroom) on different substrates. AMB Express 6: 87.

Holkar SK, Chandra R (2016) Comparative evaluation of five Pleurotus species for their growth behavior and yield performance using wheat straw as a substrate. Journal of Environmental Biology 37: 7-12.

Iqbal MSH, Rauf A, Sheikh IM (2005) Yield performance of oyster mushroom on different substrates. Int J Agric Biol 7: 900-903.

Irie T, Honda Y, Watanabe, T, Kuwahara M (2001) Efficient transformation of filamentous fungus Pleurotus ostreatus using single strand carrier DNA. Appl Microbiol Biot 55: 563-565.

Jonathan SG, Okon CB, Oyelakin AO, Oluranti OO (2012) Nutritional values of oyster mushroom (Pleurotus ostreatus) (Jacq. Fr.) Kumm. cultivated on different agricultural wastes. Nature and Science 10: 186-191.

Kumla J, Suwannarach N, Jaiyasen A, Bussaban B, Lumyong S (2013) Development of an Edible Wild Strain of Thai Oyster Mushroom for Economic Mushroom Production Chiang. Mai J Sci 40: 161-172.

Lettera V, Del-Vecchio C, Piscitelli A, Sannia G (2011) Low impact strategies to improve ligninolytic enzyme production in filamentous fungi: the case of laccase in Pleurotus ostreatus. CR Biology 334: 781-788.

Liu Y, Wang S, Yin Y, Xu F (2013) Evaluation of genetic diversity of Chinese Pleurotus ostreatus cultivars using DNA sequencing technology. Annual Microbiology 63: 571-576.

Ma AM, Shan LJ, Wang HJ, Du ZP, Xie BJ (2008) Partial characterization of a hydrophobin protein Po. HYD1 purified from the oyster mushroom Pleurotus ostreatus World J Microbiol Biotechnol 24:501-507.

Marques G, Gamelas JAF, Ruiz-Duenas, FJ, Del Rio JC, Evtuguin DV, Martinez AT, Gutierrez A (2010) Delignification of eucalypt craft pulp with manganese-substituted polyoxometalate assisted by fungal versatile peroxidase. Bioresource Technol 101: 5935-5940.

Nasim G, Malik SH, Bajwa R, Afzal M, Mian CG (2001) Effect of three different culture media on mycelia growth of oyster Chinese mushroom. J Biol Sci. 1: 1130-1133.

Ojwang D, Otieno-Onyango C, Onguso JM, Matasyoh LG, Bramwel WW, Mark-Wamalwa M, Harvey JJW (2015) Genetic diversity of Kenyan native oyster mushroom (Pleurotus). Mycologia 107: $32-38$.
Oseni TO, Dube SS, Wahome PK, Masarirambi MT, Earnshaw DM (2012) Effect of wheat bran supplement on growth and yield of oyster mushroom (Pleurotus ostreatus) on fermented pine sawdust substrate. Exp Agric Hortic 30-40.

Pala SA, Wani AH, Mir RA (2013) Evaluation of yield performance of Pleurotus sajor-caju on different agro-based wastes. Afr J Agric Res 8: 3025-3028.

Pan XL, Wang JL, Zhang DY (2005) Biosorption of $\mathrm{Pb}$ (II) by Pleurotus ostreatus immobilized in calcium alginate gel. Process Biochem 40: 2799-2803.

Piscitelli A, Del Vecchio C, Faraco V, Giardina P, Macellaro G, Miele A, Pezzella C, Sannia G (2011) Fungal laccases: versatile tools for lignocellulose transformation. CR Biol. 334: 789-794.

Pokhrel CP, Kalyan U, Budathoki U, Yadav RKP (2013) Cultivation of Pleurotus sajor-caju using different agricultural residues. Int $\mathrm{J}$ Agric Pol Res. 1: 19-23.

Poppe J (2000) Use of Agricultural Waste Materials in The Cultivation of Mushrooms. In Proceedings of $15^{\text {th }}$ İnternational Congress on The Science and Cultivation of Edible Fungi. Rotterdeam, Balkema pp. 3-23.

Rajak S, Basu M (2011) Yield, fruit body diameter and cropping duration of oyster mushroom (Pleurotes sajor caju) grown on different grasses and paddy straw as substrates. European J Medicinal Plants 1: 11-17.

Ruiz-Duenas FJ, Fernandez E, Martinez MJ, Martinez AT (2011) Pleurotus ostreatus heme peroxidases: an in silico analysis from the genome sequence to the enzyme molecular structure. CR Biol 334: 795-805.

Salvachua D, Prieto A, Lopez-Abelairas M, Lu-Chau T, Martinez AT, Martinez MJ (2011) Fungal pretreatment: an alternative in secondgeneration ethanol from wheat straw. Bioresource Technol 102: 7500-7506.

Sanchez C (2010) Cultivation of Pleurotus ostreatus and Other Edible Mushrooms.Applied Microbiology and Biotechnology 85: 1321-1337.

Shabtay A, Hadar Y, Eitam H, Brosh A, Orlov A, Tadmor Y, Zhaki I, Kerem Z (2009) The potential of Pleurotus-treated olive mill solid waste as cattle feed. Bioresource Technol 100: 6457-6464.

Silvana A, Pianzzola MJ, Soubes M, Cerdeiras MP (2006) Biodegradation of agro-industrial wastes by Pleurotus spp. for its use as ruminant feed. Elect J Biotech 9: 215-220.

Stamets P (2000) Growing Gourmet and Medicinal Mushrooms, Ten Speed Press $3^{\text {rd }}$ edn, New York. 